\title{
Atitudes e comportamentos de estudo em alunos de CURSO SUPERIOR: DIFERENÇAS ENTRE GÊNEROS ${ }^{\star}$
}

\author{
Larissa do Nascimento Lemos; Camila Teresa Ponce Leon de Mendonça; \\ Maria Fabrícia Queiroga da Costa; Tatiana Schneider; Alisson de \\ Menezes Pontes; Débora Hipólito Lisboa $\star \star$

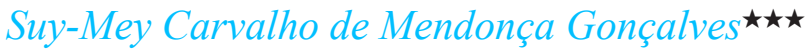

Palavras-chave: diferença entre gêneros; hábitos de estudo; atitudes e comportamentos.

Estudos têm procurado demonstrar diferenças de gêneros em várias áreas (social, de personalidade, cultural, etc.). Tais diferenças explicam comportamentos e influenciam a adoção de novos comportamentos. Nessa busca por diferenças, pesquisas sobre diferenças de gêneros em investimentos dos estudantes do Ensino Superior nas suas atividades de estudo são ainda incipientes. Assim sendo, este estudo buscou aplicar o Inventário de Atitudes e Comportamentos Habituais de Estudo (IACHE-sup), em estudantes do ensino superior em uma instituição de ensino privado na cidade de João pessoa - PB. A amostra da pesquisa foi composta por 458 alunos, com idades entre 17 a 58 anos, com a maior porcentagem de mulheres, e distribuída pelos cursos de psicologia, administração, direito e fisioterapia. Os alunos responderam, durante os intervalos das aulas, a um questionário contendo 44 itens, distribuídos em seis dimensões (compreensivo, reprodutivo, percepções pessoais, motivação, organização do estudo, satisfação). Análises descritivas e inferenciais através de testes $t \mathrm{e}$ análises de variância evidenciaram que o gênero feminino apresentou maior média no fator reprodutivo, voltado à memorização do conteúdo apreendido e na retenção via repetição da matéria dada. Em relação aos demais fatores não foram encontradas diferenças significativas. Observou-se, também, que o sexo masculino destaca-se no fator de organização do estudo, dado pela motivação intrínseca às atividades de estudo, e gosto pela tarefa ligada à aprendizagem do curso. Tais resultados apontam para questões culturais e corroboram pesquisas, as quais mostram que mulheres passam mais tempo fixando conteúdos e, portanto, o memorizam mais, e que, os homens são mais organizados e disciplinados em relação aos estudos. Portanto, verifica-se que há diferenças significativas entre os gêneros nessa temática e que especialistas podem utilizar-se destes achados para investigações futuras e elaboração de recursos pedagógicos a esse estrato amostral.

* Trabalho apresentado no IV congresso de Avaliação Psicológica, durante o período de 29/07/2009 a 01/08/2009, na cidade de Campinas São Paulo.

$\star \star$ Graduandas do Curso de Psicologia da UNIPÊ - Centro Universitário de João Pessoa

$\star \star \star$ Orientadora. Doutora em Psicologia pela Universidade de Brasília. Professora titular do Centro Universitário de João Pessoa e coordenadora adjunta do curso de Psicologia.

E-mail: suymey@hotmail.com 